\title{
Children with Small Chests
}

\author{
D. HULL and N. D. BARNES \\ From The Hospital for Sick Children, Great Ormond Street, London
}

\begin{abstract}
Hull, D., and Barnes, N. D. (1972). Archives of Disease in Childhood, 47, 12. Children with small chests. The volume of the thoracic cage may be severely restricted by faulty rib growth due to a variety of bone diseases. At one extreme the thorax may be too small to permit adequate lung expansion after birth; at the other, the abnormality may only be recognized by examination of an $x$-ray. However, in a small group of infants the deformity, though not obvious clinically, may be severe enough to cause fatal respiratory failure in the first few months of life. It is possible that some of these infants may be saved by surgical enlargement of the thoracic cage.
\end{abstract}

Children with a variety of disorders which affect the skeleton may have inadequate development of the thoracic cage and as a consequence suffer from severe respiratory difficulty. This is a cause of morbidity and mortality which is rarely mentioned in paediatric textbooks, and therefore we have briefly reviewed the bone diseases in which we are aware that this complication occurs, selecting case histories which illustrate the respiratory problems. The review is primarily concerned with the effects of limited rib growth; respiratory disorders secondary to curvature of the spine or to sternal deformities are not discussed.

Growth in length of the ribs occurs chiefly at the costochondral junctions. When this process is disturbed a characteristic chest deformity results. The thorax is small and usually has a 'fetal' or 'bell' shape: narrow in the upper part with a slight flaring of the lower ribs. The circumference is reduced. The upper ribs lie horizontally and the clavicles appear high. The ribs are short and the costochondral junctions lie laterally, often in the anterior axillary lines, and may be expanded and irregular. Chest $x$-rays demonstrate the small lung fields which often show opacities suggesting collapse consolidation. The heart appears enlarged due to the relatively small thorax, and the cardiothoracic ratio is increased. The diaphragm is depressed and the liver and spleen, though of normal size, are palpable well below the costal margins. The abdomen appears distended. The chief clinical features are illustrated diagrammatically in Fig. 1.

The characteristic respiratory pattern is often

Received 16 July 1971. more striking than the mere size of the chest. Breathing is rapid and shallow and entirely abdominal, virtually no movement of the chest occurring even when there is obvious respiratory distress with contraction of the accessory muscles and soft tissue indrawing. Rales may be present over the lung fields in the absence of overt infection.

\section{Thoracic Dystrophy}

Thoracic dystrophy, which has also been called 'asphyxiating' or 'infantile' thoracic dystrophy and 'thoracic-pelvic-phalangeal' dystrophy, was first described by Jeune et al. in 1954. This condition is a generalized chondrodystrophy which principally affects the thoracic cage. More than 50 cases have now been reported, of which the majority have died within the first year of life from respiratory problems. However, the spectrum of the disease extends from a condition which is lethal in the neonatal period, to a minor and often undetected skeletal abnormality. The extrathoracic manifestations are also variable; there are usually obvious dystrophic changes in the pelvis, the limbs are a little short with widening and irregularity of the metaphyses, and there is often a characteristic pyriform deformity of the epiphyses of the short tubular bones. The spine and skull are normal (Langer, 1968). An association with renal disease has been described (Herdman and Langer, 1968). Various other features such as polydactyly, dental anomalies, and hypoplasia of the abdominal muscles have been described in a small number of cases, and it seems probable that more than one entity may be represented. Histologically, dystrophic changes have been demonstrated at the 
costochondral junctions with less marked changes at other sites. In most cases the condition appears to be inherited as an autosomal recessive character (Barnes, Hull, and Symons, 1969).

We have previously described 2 sibs with the typical thoracic deformity whose mother also shows similar but less severe skeletal abnormalities. The first child died from asphyxia at the age of 6 weeks and necropsy studies suggested that the lungs were not hypoplastic. A partially successful attempt was made to enlarge the chest cage of the second child (Barnes et al., 1969; Barnes et al., 1971).

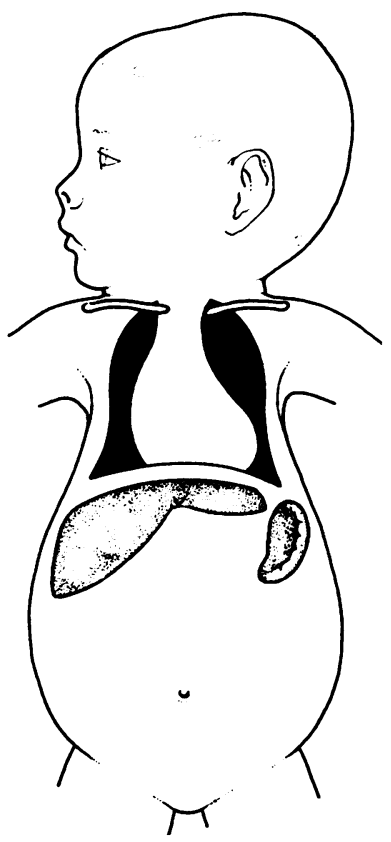

FIG. 1.-Thoracic dystrophy. This diagram illustrates the clinical features of infants with small chests. The normal sized heart appears enlarged and the clavicles ride high. The abdomen appears distended and the liver and spleen which are of normal size are easily palpable.

We have subsequently come across 6 more children with this condition, 2 sibs in each of 3 families. There was no parental consanguinity or other relevant family history. The 2 children of the first family were both girls born with thoracic deformity and short limbs. They suffered severe respiratory distress from birth and died at 24 hours and at 3 days. The radiological changes were characteristic, and necropsy in both cases revealed no abnormality other than the skeletal changes and partially unexpanded lungs.
In the second family the first child, a boy, was noted to have a marked thoracic deformity at birth, but no other skeletal abnormality was present. Skull circumference was $36 \mathrm{~cm}$ and the circumference of the thorax at the nipples $26 \mathrm{~cm}$. The liver and spleen were easily palpable. Cyanosis and respiratory distress were present from birth and the rapid respiratory rate and persistent rales were heard. He died at 3 days. At necropsy the very small chest cage was apparent and the ribs were short with expanded costochondral junctions. The lungs were almost unexpanded, the right weighing $17 \mathrm{~g}$ and the left $19 \mathrm{~g}$. There was a left hydroureter with stenosis of the ureterovesical junction. A female infant with no abnormality was born next, and then another male with an identical chest deformity to his male sib. He also developed early respiratory difficulty then improved a little and was allowed home. He was readmitted to hospital twice in the first few weeks of life with further respiratory difficulty, presumably from minor infections, and at 2 months was overwhelmed

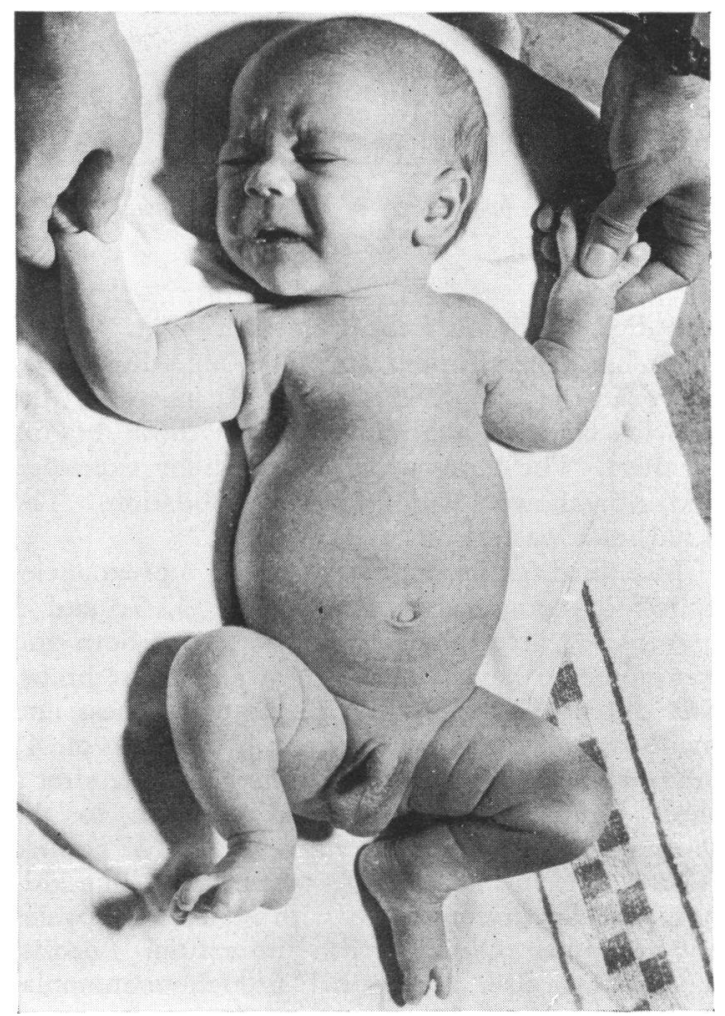

FIG. 2.-An infant with thoracic dystrophy aged 5 weeks. He died with a trivial respiratory infection at 8 weeks of age. 


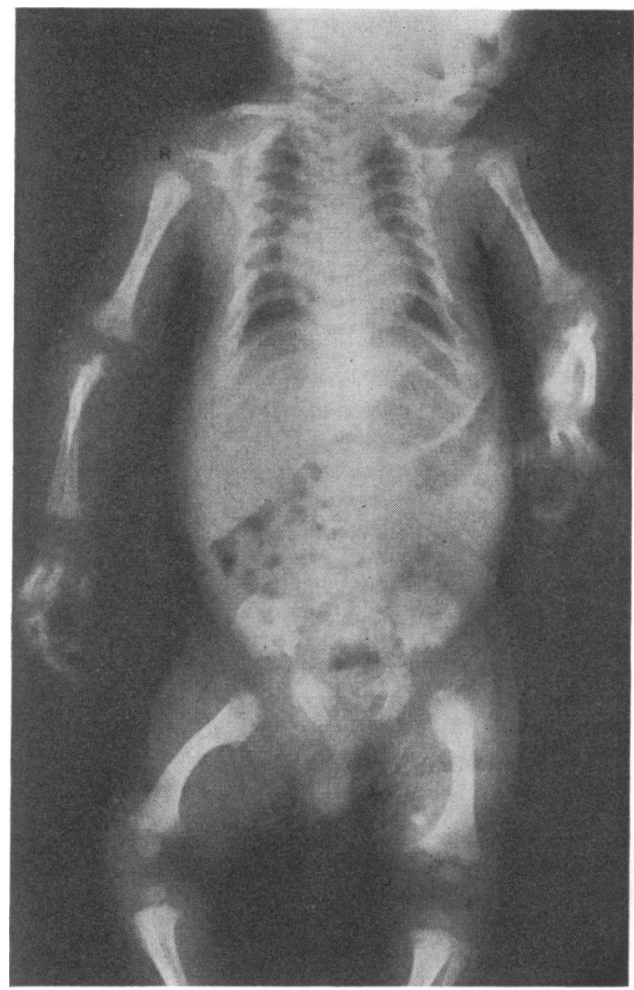

FIG. 3.-Whole body $\mathrm{x}$-ray of the infant shown in Fig. 2 (compare Fig. 1).

and died rapidly in a third episode. Fig. 2 and 3 show his general appearance and his whole body $x$-ray at the age of 5 weeks. At necropsy the skeletal changes were identical to those of his brother. The lungs were only partially expanded and also showed widespread consolidation. The renal tract was normal.

In a third family the mother's first 3 pregnancies ended in spontaneous abortion at 3, 7, and 5 months. A live female infant was then born and was noted to have a small chest and short limbs. She did not suffer serious respiratory illness and made satisfactory progress until the age of $4 \frac{1}{2}$ years when she became ill and died at home after a short illness. At necropsy in addition to the skeletal deformities there was evidence of cardiac failure and chronic glomerulonephritis. The kidneys were both contracted with adherent capsules and granular cortices with interstitial fibrosis. There was also a terminal bronchopneumonia. Another boy was born 3 years later and showed identical skeletal deformities. He also made satisfactory progress without an excess of respira- tory disease for the first 2 years, but then he developed polyuria and polydipsia, followed by progressive dyspnoea and lassitude. At $3 \frac{1}{2}$ years, uraemia, hypertension, and cardiac failure were shown. He died shortly after admission to hospital. At necropsy the chief findings were the contracted chest cage, expanded costochondral junctions, moderately shortened limbs, and stubby fingers. The lower femoral epiphyses were wide and irregular with central 'points' dipping into the metaphyses. No other skeletal abnormality was noted. The lungs were congested and oedematous, the right weighing $152 \mathrm{~g}$ and the left $108 \mathrm{~g}$. The kidneys were very small, right $23 \mathrm{~g}$, left $24 \mathrm{~g}$; the capsules were thick and adherent, the subcapsular surface pale and granular; there was complete loss of renal architecture and of corticomedullary demarcation. The pelvis and lower renal tracts were normal.

\section{Achondroplasia}

The chief features of this condition and the dominant inheritance are well established (Langer, Baumann, and Gorlin, 1967), but the occurrence of respiratory complications has received little prominence except in relation to 'thanatophoric dwarfism' which is described below. However, there is no doubt that in classical achondroplasia the small chest cage may cause severe respiratory difficulty, as in the following case.

Both parents are dwarfed, the mother $119 \mathrm{~cm}$ tall, and the father $142 \mathrm{~cm}$. The mother shows the features of classical achondroplasia, but the father shows neither clinical nor radiological features compatible with this diagnosis. Both their children, however, suffered from achondroplasia. Both were boys, born by caesarean section, and they had respiratory difficulty from birth. The first child had continuing respiratory distress and died at 68 days from respiratory failure. The second child also developed severe respiratory distress from birth. Fig. 4 shows his general appearance at the age of 18 days. He showed the features of classical achondroplasia and had a remarkably small and rigid chest. The chest circumference at the nipple line was $28.5 \mathrm{~cm}$. His respiratory rate was $100 / \mathrm{min}$, he was cyanosed in air, and fine rales were audible all over the chest. The liver was palpable $3 \mathrm{~cm}$ below the right costal margin. Investigations showed a respiratory acidosis, $\mathrm{PCO}_{2}$ 57-77 mm Hg. In spite of an oesophageal pressure swing of $24 \mathrm{~cm} \mathrm{H}_{2} \mathrm{O}$ he achieved a tidal volume of only $10 \mathrm{ml}$. His condition deteriorated further so tracheostomy was performed and artificial ventilation started. Total static compliance 


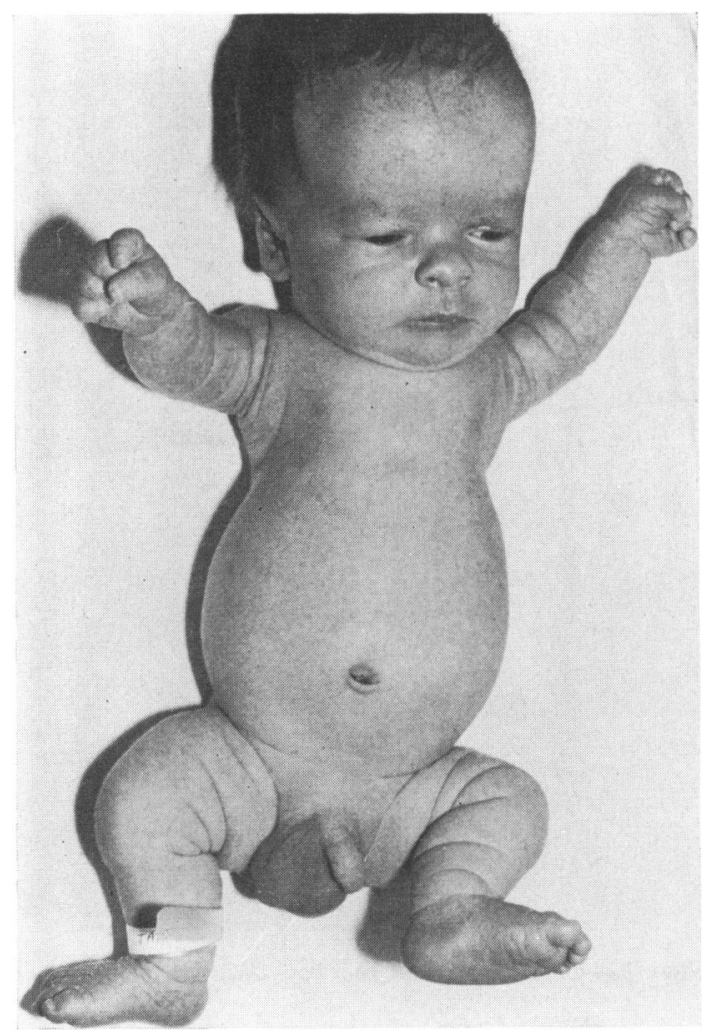

FIG. 4.-An infant with achondroplasia who had increasing respiratory difficulty from birth and who died when he was 68 days old.

under anaesthesia was very low at $0.75 \mathrm{ml} / \mathrm{cm} \mathrm{H}_{2} \mathrm{O}$. It proved impossible to ventilate him adequately and he died 10 days later.

\section{Thanatophoric Dwarfism}

Thanatophoric means 'death-delivering'. This term was first used by Maroteaux, Lamy, and Robert (1967) who described this condition and differentiated it from classical achondroplasia. The condition is a congenital chondrodystrophy characterized by very short limbs, a relatively large head, and narrow thorax. The children suffer from severe respiratory distress and usually succumb within the first few hours of life. Clinically the condition is indistinguishable from achondroplasia but may be differentiated by a number of radiological features and possibly also by histology (Rimoin et al., 1969; Kaufman et al., 1970). Whether this is indeed a true entity or merely represents the most severely affected cases of achondroplasia or possibly the homozygous form of the condition, there is no doubt about the severe respiratory problems and the cause of death.

Fig. 5 is a photograph of a child with this condition born to normal parents with two normal children and no other relevant history. Spontaneous respiration was established but was rapid and shallow and the child remained cyanosed. He deteriorated and died at $\mathbf{1 5}$ hours. Though few have been reported, most paediatricians will have seen similar cases and this condition is probably not rare.

\section{Ellis-Van Creveld Syndrome}

This condition, otherwise known as chondroectodermal dysplasia, was described by Ellis and Van Creveld in 1940, and is inherited as an autosomal recessive character. The chief features are dwarfism with short limbs especially distally, polydactyly, and dysplastic hair, fingernails, and teeth. Other abnormalities also occur including partial harelip, congenital heart disease in $50 \%$ (often a

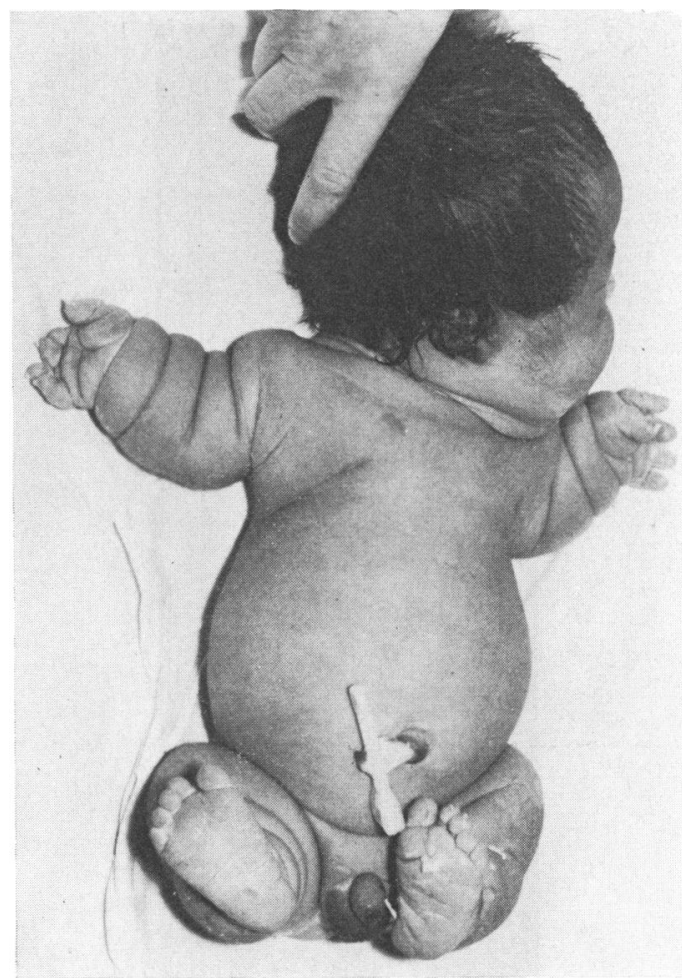

FIG. 5.-A thanatophoric dwarf who died 15 hours after birth. 
single atrium), and a small thorax, first noted by Smith and Hand in 1958. There is a high mortality from cardiac and respiratory problems. McKusick et al. (1964) reported 52 cases occurring in the isolated and inbred religious community, the Old Order Amish of Lancaster County, Pennsylvania, of which 20 died before the age of 2 weeks and 30 before 6 months. It has been suggested that thoracic dystrophy may be a variant of the EllisVan Creveld syndrome (Hanissian, Riggs, and Thomas, 1967).

Fig. 6 shows a child with this condition at 8 years, and Fig. 7 his chest $x$-ray. $\mathrm{He}$ is the oldest of three sibs; his brother and sister are normal; his parents are healthy and unrelated. The diagnosis was made at the age of 9 months because of his shurt limbs, very narrow thorax, 6 digits on each hand, congenital heart disease, and dysplastic fingernails. Throughout his youth he suffered from repeated respiratory infection and his exercise tolerance was poor. However he improved with age and was well and able to manage a sedentary job at the age of 17 .

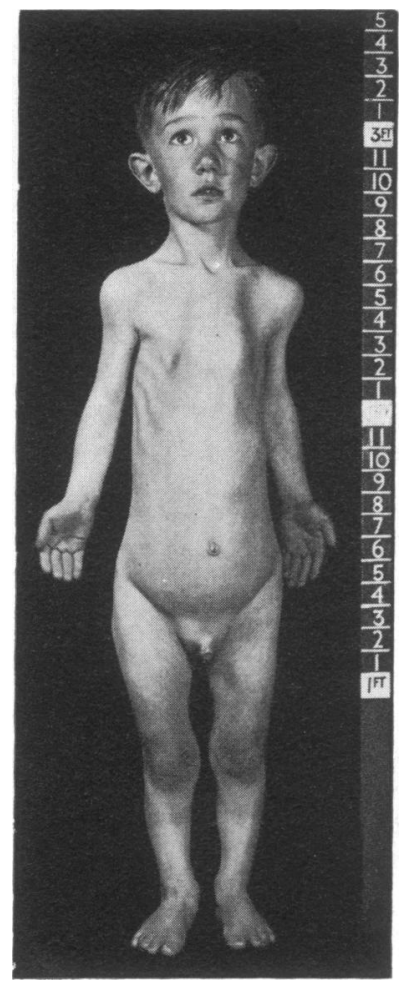

FIG. 6.- $A$ boy aged 8 years showing the chest deformity associated with the Ellis-Van Creveld syndrome.

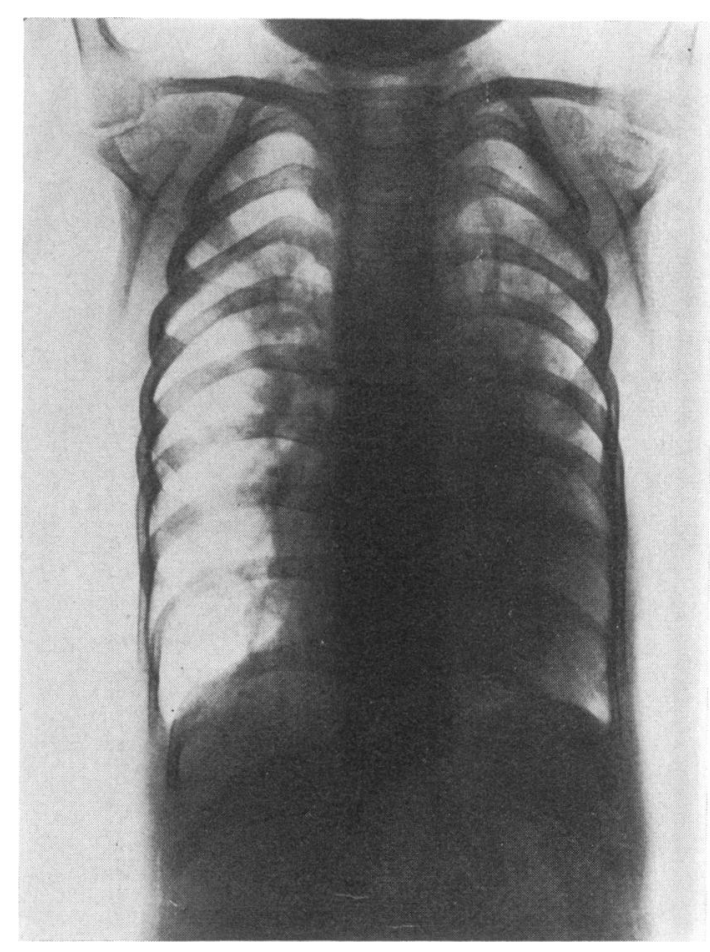

Fig. 7.-Chest $\mathrm{x}$-ray of the boy illustrated in Fig. 6.

\section{Diastrophic Dwarfism}

This condition was described in 1960 by Lamy and Maroteaux who also suggested the use of the term 'diastrophic', which is borrowed from geology where it implies bending of the earth's crust, to signify the characteristic bending of the spine and limbs. Diastrophic dwarfism is inherited as an autosomal recessive character. The chief features are short limbs, club foot, joint contractures, and scoliosis. Other features which may be present include deformed pinnae with cysts which may calcify or ossify, and cleft palate (Wilson, Chrispin, and Carter, 1969). These infants may suffer severe respiratory difficulty in infancy. This may, in part, be due to upper airway obstruction as the mandible may be poorly formed and, as in the Pierre-Robin syndrome, the tongue tends to fall back through the palatal cleft. However, the chest may be very small, and respiratory problems may occur before the scoliosis, which is not present at birth, develops.

The small chest appeared to be the major factor in 2 infants with the features of this condition who died of respiratory failure. In neither case were the parents related and there were normal sibs in 
both families. Both infants developed respiratory difficulty immediately after birth, which was only partially relieved by insertion of an airway. Progressive respiratory failure occurred and the infants died at 10 and 12 days. Respiratory measurements obtained in one child showed a respiratory rate of $60 / \mathrm{min}$ and a tidal volume of $30 \mathrm{ml}$ for an oesophageal swing of $27 \mathrm{~cm} \mathrm{H} \mathrm{H}_{2} \mathrm{O}$. Static compliance measurements performed immediately after death showed a total static compliance of $3 \mathrm{ml} / \mathrm{cm} \mathrm{H}_{2} \mathrm{O}$, chest wall $20 \mathrm{ml} / \mathrm{cm} \mathrm{H}_{2} \mathrm{O}$, and lung $3 \cdot 7 \mathrm{ml} / \mathrm{cm}$. At necropsy one child had consolidation in the left lower lobe but in the other child there was only minimal patchy consolidation in the lungs.

\section{Other Conditions}

Spondyloepiphysial dysplasia is another condition that results in short limbs and a small thorax (Spranger and Langer, 1970). Breathing may be so restricted that death occurs in the first few days of life (Farriaux, Dubois, and Fontaine, 1971). In the only patient we have seen with this disorder, respiratory difficulties occurred early in life. Respiratory function at $\mathbf{1 4}$ months of age was limited but adequate. There are numerous reports of chest deformities associated with abnormalities elsewhere, e.g. McNicholl et al. (1970); Van Benthem et al. (1970), and no doubt more will be described.

We have seen progressive collapse of the chest wall in hypophosphatasia, Pyles disease, and rickets. Respiratory failure may also be a terminal event in children with mucopolysaccharide storage disorders. Commonly, in the latter, there is upper airway obstruction due to deformity of the facial bones and thickening of the soft tissues of the upper airway, but some degree of thoracic deformity is often present, which may or may not be associated with spinal curvature (McKusick, 1966).

Two sibs with a disorder of mucopolysaccharide storage which was atypical in some features and was not fully characterized, showed severe restrictive pulmonary disease due to inadequate development of the thoracic cage. The first child of healthy unrelated West Indian parents, a boy, died from respiratory disease at the age of 3 months. Two healthy daughters were then born and made good progress, but a third daughter showed multiple abnormalities and gross developmental retardation. She had an abnormal facies, corneal clouding, hypertrophy of the alveolar ridges, a small chest, multiple joint contractures, and radiological changes compatible with a mucopolysac- charide storage disorder. There was no visceral enlargement. The urine showed an excess of mucopolysaccharides and a rectal biopsy confirmed the diagnosis. She suffered repeated respiratory infections and died at 2 years of pneumonia and meningitis. A fourth daughter showed almost identical features. In this child abnormal inclusions were also noted in the lymphozytes and fibroblasts. She too suffered from repeated respiratory infection leading rapidly to severe respiratory distress. There was no evidence of upper airway obstruction and no significant spinal curvature. Her chest at the age of 4 months is shown in Fig. 8. She died from pneumonia at 1 year.

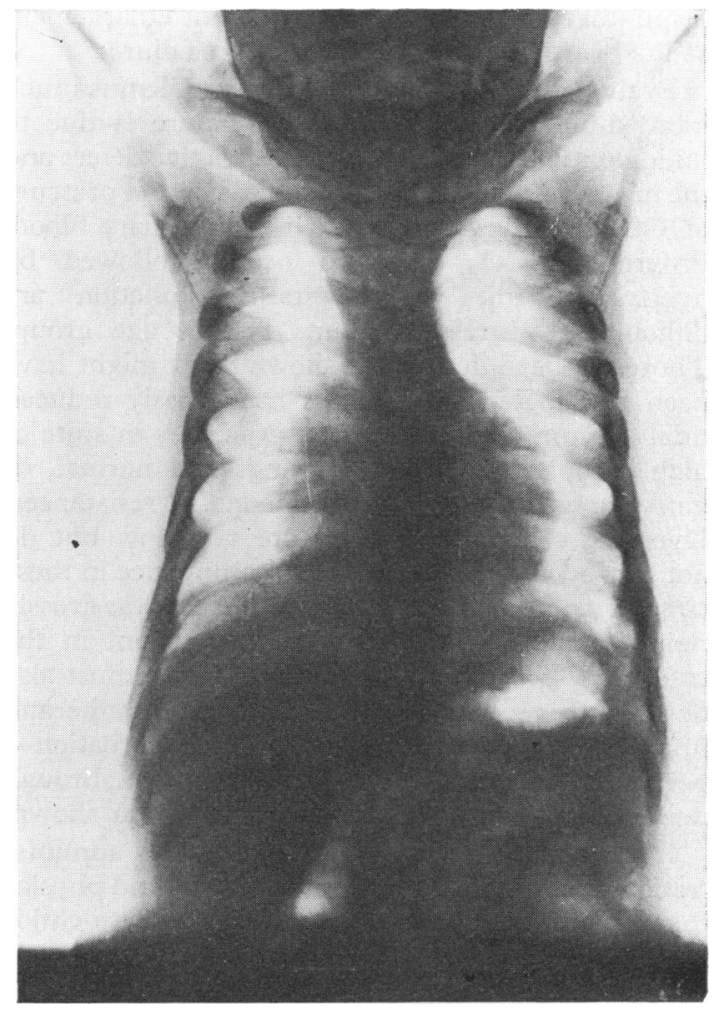

FIG. 8.-The chest x-ray of a child with an obscure mucopolysaccharide storage disorder which was associated with a very small thoracic cage.

\section{Discussion}

Thus a number of conditions which affect the skeleton may delay or disturb growth of the ribs sufficiently to cause serious impairment of pulmo- 
nary function in childhood. The majority are 'chondrodystrophies', in which there is a disturbance of endochondral ossification. Though all the individual diseases discussed are rare, it is probable that the total number of children affected is not inconsiderable. Some of these children have multiple handicaps but in others the respiratory problems may be the only significant disability. In most cases the primary diagnosis can be made by examination of the skeleton radiologically.

When a child is severely affected the respiratory problem is usually obvious both clinically and radiologically, but in radiographs which include only the chest the small size of the thoracic cage in relation to the size of the child may not be obvious. It is important also to avoid misinterpreting the respiratory difficulty and the apparent enlargement of the heart and liver as due to heart failure.

Evaluation of the severity of the problem is much more difficult. The respiratory failure is due to underventilation caused by the restrictive defect and the most useful index is probably the partial pressure of $\mathrm{CO}_{2}$ in arterial or 'arterialized' capillary blood. Progressive $\mathrm{CO}_{2}$ retention occurs followed by hypoxia. Studies of respiratory function are difficult in distressed infants in this age group. Those we have done have shown what might have been anticipated; the infants had grossly reduced tidal volumes and crying vital capacities in spite of high oesophageal pressure swings and normal, or moderately raised, total pulmonary resistances. Dynamic compliance values are very low but do not give a valid measure of lung compliance in these circumstances. Total static compliance was grossly reduced due to the chest wall component in the cases in which it was measured. There must also be obvious reductions in thoracic gas volume and functional residual capacity, with ventilationperfusion mismatch due to shunting through unexpanded lung, but these have not been shown.

In treatment, general measures such as administration of oxygen, correction of acidosis, and physiotherapy are, of course, important. As these children may succumb very rapidly to apparently trivial infection, vigorous and adequate antibiotic therapy must be given at the first sign of infection. Artificial ventilation may prove difficult or even impossible and only has a place as a temporary supportive measure when there is a clear prospect of improvement. When other measures fail operation seems theoretically to be justified. Splitting and fixation of the sternum can provide a considerable increase in thoracic volume and, if adequate stability of the thoracic cage can be achieved, should not disrupt the mechanics of breathing.
However the technical problems are considerable and the operation was only partially successful in the single infant with thoracic dystrophy in whom $\stackrel{\vec{P}}{+}$ it has been attempted (Barnes et al., 1971).

The prognosis for respiratory function depends on the capacity of the ribs for growth and of the lungs for expansion to an adequate volume. The $\stackrel{\mathbb{Q}}{\Omega}$ natural history of these diseases suggests that the respiratory problems are most severe in the first few months and that, if the children survive the first year, in most cases, the respiratory problems will resolve. For this reason, in infants where the associated abnormalities are not crippling, early recognition and treatment of the respiratory problem are vital.

We wish to thank Dr. C. B. M. Warren, Dr. Nigel $\vec{N}$ Royston and Dr. G. H. Newns for permission to publish details about children under their care.

\section{REFERENCES}

Barnes, N. D., Hull, D., Milner, A. D., and Waterston, D. J. (1971). Chest reconstruction in thoracic dystrophy. Archives of Disease in Childhood, 46, 833.

Barnes, N. D., Hull, D., and Symons, J. S. (1969). Thoracic dystrophy. Archives of Disease in Childhood, 44, 11.

Ellis, R. W. B., and Van Creveld, S. (1940). Syndrome characterised by ectodermal dysplasia, polydactyly, chondro-dysplasia and congenital morbus cordis. Archives of Disease in Childhood, $15,65$.

Farriaux, J. P., Dubois, B., and Fontaine, G. (1971). La dysplasie spondylo-épiphysaire congénitale. Pédiatrie, 26, 215.

Hanissian, A. S., Riggs, W. W., Jr., and Thomas, D. A. (1967). Infantile thoracic dystrophy: a variant of the Ellis-Van Creveld syndrome. Fournal of Pediatrics, 71, 855 .

Herdman, R. C., and Langer, L. O. (1968). The thoracic asphyxiant dystrophy and renal disease. American fournal of Diseases of Children, 116, 192.

Jeune, M., Carron, R., Béraud, C., and Loaec, Y. (1954). Polychondrodystrophie avec blocage thoracique d'évolution fatale. Pédiatrie, 9, 390.

Kaufman, R. L., Rimoin, D. L., McAlister, W. H., and Kissane, L. M. (1970). Thanatophoric dwarfism. American fournal of Diseases of Children, 120, 53.

Lamy, M., and Maroteaux, P. (1960). Le nanisme diastrophique. Presse Médicale, 68, 1977.

Langer, L. O., Jr. (1968). Thoracic-pelvic-phalangeal dystrophy. Radiology, 91, 447.

Langer, L. O., Jr., Baumann, P. A., and Gorlin, R. J. (1967). Achondroplasia. American fournal of Roentgenology, 100, 12.

McKusick, V. A. (1966). Heritable Disorders of Connective Tissue, 3rd ed. C. V. Mosby, St. Louis.

McKusick, V. A., Egeland, J. A., Eldridge, R., and Krusen, D. E. (1964). Dwarfism in the Amish. I. The Ellis-Van Creveld syndrome. Bulletin of the fohns Hopkins Hospital, 115, 306.

McNicholl, B., Egan-Mitchell, B., Murray, J. P., Doyle, J. F., Kennedy, J. D., and Crome, L. (1970). Cerebro-costomandibular syndrome. Archives of Disease in Childhood, 45, 421.

Maroteaux, P., Lamy, M., and Robert, J. M. (1967). Le nanisme thanatophore. Presse Médicale, 75, 2519.

Rimoin, D. L., Hughes, G. N. F., Kaufman, R. L., and McAlister, W. H. (1969). The chondrodystrophies: clinical and histopathological correlations. (Abst.) Fournal of Laboratory and Clinical Medicine, 74, 1002.

Smith, H. L., and Hand, A. M. (1958). Chondroectodermal dysplasia (Ellis-Van Creveld syndrome): report of two cases. Pediatrics, 21, 298. 
Spranger, J. W., and Langer, L. O., Jr. (1970). Spondyloepiphyseal dysplasia congenita. Radiology, 94, 313.

Van Benthem, L. H. B. M., Driessen, O., Haneveld, G. T., and Rietema, H. P. (1970). Crytorchidism, chest deformities, and other congenital anomalies in three brothers. Archives of Disease in Childhood, 45, 590.
Wilson, D. W., Chrispin, A. R., and Carter, C. O. (1969). Diastrophic dwarfism. Archives of Disease in Childhood, 44, 48.

Correspondence to Dr. David Hull, The Hospital for Sick Children, Great Ormond Street, London WC1N 3JH. 